\title{
Two measures of activity in genetically defined mice as a function of strain, time of day, and previous experience
}

\author{
DUDLEY F. PEELER \\ University of Mississippi Medical Center, Jackson, Mississippi
}

\begin{abstract}
Genetically defined adult mice from progenitor strains C57BL/6 and BALB/c and the 7 recombinant inbred strains derived from them were tested at one of five times of day for amount of locomotor and investigatory activity in three 16-min sessions. Strain, sex, time of day, and experiential factors are shown to interact in variable and complex fashion. Previous reports of a single major gene's determining activity level are contradicted. Observed genetically determined differences were not in concordance with strain distribution patterns for other genetically determined traits. Interpretation of locomotor and investigatory activity as separable behaviors is supported. Habituation (activity decrement) both within and between sessions is added to the behaviors amenable to behavior genetic investigations.
\end{abstract}

Simplicity of design of experiments is desirable in that it limits the complexity of data collection, analyses, and interpretation. Nevertheless, determinants of behavior, both genetic and experiential, interact. Simplicity of design is most readily achieved by imposing constraints that severely limit the possibility of finding any but main effects; meaningful interactions may be obscured or ignored. Variables that might be expected to be significant interacting influences on a variety of behaviors, but that often are not considered or are purposely eliminated from consideration, include the genetic influences of strain and sex, as well as the experiential factors time of day and previous exposure.

Assessments of genetic influences often utilize measures of activity. Among the most popular measures are "exploratory" activity in an open field (e.g., DeFries, Grevais, \& Thomas, 1978; DeFries, Hegmann, \& Halcomb, 1974), wheel running (e.g., Oliverio \& Malorni, 1979), and tilt cages (e.g., Oliverio, Eleftheriou, \& Bailey, 1973). The last device has been used to determine that exploratory activity is primarily influenced by a single major gene (Moisset, 1977; Oliverio et al., 1973), at least for shortduration (10 $\mathrm{min}$ ) measurements (Oliverio \& Messeri, 1973). However, efforts to extend these findings to other exploratory activity measures have been unsuccessful (Peeler \& Nowakowski, 1987), rendering problematic the designation of exploratory activity as a specific unitary behavior or trait. Furthermore, level of activity has been demonstrated to be a function not only of genetic background but also of measurement technique (Foshee,

Correspondence may be sent to Dudley F. Peeler, Department of Neurosurgery, University of Mississippi Medical Center, Jackson, MS 39216.
Vierck, Meier, \& Federspiel, 1965; Lassalle \& le Pape, 1978; Peeler \& Nowakowski, 1987; Simmel, 1976; Simmel \& Eleftheriou, 1977; Simmel, Eleftheriou, Haber, \& Harshfield, 1977), lighting conditions (Blizard \& Bailey, 1979; Isaacson \& McClearn, 1978; Lassalle \& le Pape, 1978; Oliverio \& Messeri, 1973; le Pape \& Lassalle, 1984), and age of the subjects (le Pape \& Lassalle, 1984). There are indications of circadian influences upon activity (Lassalle \& le Pape, 1978; Oliverio \& Malorni, 1979) and their interaction with genetic factors (Peeler, 1986).

Of the genetically defined mouse strains, the C57BL/6 and $B A L B / C$ are among the most frequently used. The BALB/c and C57BL/6 strains are particularly appropriate for genetic investigations, because seven fixed recombinations of the genomes of these two progenitor (P) strains have been derived as recombinant inbred (RI) strains (Bailey, 1981). Comparisons of behavior between C57BL/6 and BALB/c (and their RI strains) are of added interest since the BALB/c strain has been reported to possess a defect in pyramidal cell arrangement and mossy fiber innervation in hippocampal area CA3 (Nowakowski, 1984), and the hippocampus has been implicated in a variety of behaviors, including locomotion and exploration (Chozick, 1983). This hippocampal lamination defect (Hld) is apparently determined by a single gene (Nowakowski, 1984).

The present study extends the findings concerning activity measurement in C57BL/6, BALB/c, and the RI strains derived from them by demonstrating an effect of time of day that varies as a function of strain, type of activity measured, and sex. This offers further opportunity to assess possible single-gene effects upon activity measures and the relation of these measures to Hld. In addition, the possible relation of genetic and circadian variables to 
habituation of activity within and between measurement sessions is explored.

\section{METHOD}

\section{Subjects}

The subjects were adult male and female mice from each of the C57BL/6By and BALB/cBy progenitor strains and their seven RI strains: CXBD/By, CXBE/By, CXBG/By, CXBH/By, CXBI/By, $\mathrm{CXBJ} / \mathrm{By}$, and $\mathrm{CXBK} / \mathrm{By}$. All subjects were born in the Neurosurgery Laboratory, University of Mississippi Medical Center, animal colony from stock originally purchased from Jackson Laboratory (Bar Harbor, Maine). A total of 900 mice (450 of each sex) was used. An attempt was made to test all subjects at approximately 90 days of age. Although most subjects were within a week or two of this age at testing, the range was from 70 to 120 days.

All subjects were housed in the animal colony in standard clear plastic cages $(17 \times 27 \times 12.5 \mathrm{~cm}), 2$ to 6 animals to a cage. The fluorescent lighting, temperature, and humidity in the room were automatically controlled. Food and water were available ad lib. The room lights were turned on at $0600 \mathrm{~h}$ and off at $1800 \mathrm{~h}$.

\begin{abstract}
Apparatus
Activity was measured in a runway device (Peeler, 1972; Peeler \& Nowakowski, 1987), with photo beams intersecting the long axis at $17.8 \mathrm{~cm}$ from either end and at the midpoint and with 15 "freeform" metal objects spaced equal distances apart along one side. This arrangement permits unobstructed locomotion the full length of the runway but provides virtually constant opportunity for investigatory activity that does not involve locomotion. Locomotor activity was measured as the number of photobeam interruptions; investigatory activity was measured as the number of contacts with the objects arrayed along one side of the runway. (The mouse, when touching an object, completes a circuit with the metal floor of the runway. A transistor trigger circuit, which carries no more than $10 \mu \mathrm{A}$ of current, operates a counter with each such contact.) The objects included metal covers for electronic tubes, circular wire brushes, various shapes created from 14-ga copper wire, a flat metal bar, shafts, spacers and stanchions, and bolts with threads. A metal washer ( 1 in. in diameter) formed the base of each, from which the object extended vertically. Two of the objects protruded slightly outside this dimension. Not all of the objects were symmetrically shaped; all differed to some extent in surface contour and/or texture. The inside dimensions of the device were $85 \times 10.2 \times$ $10.2 \mathrm{~cm}$. A transparent (glass) cover permitted observation while discouraging the mice's attempts to climb or escape.
\end{abstract}

\section{Procedure}

Ten male and 10 female mice of each of the nine strains were tested at one of five time periods during the day: 0700-0900, $1000-1200,1300-1500,1600-1800$, or $1900-2100 \mathrm{~h}$. (These periods will subsequently be referred to as TOD [time of day] 1 , $2,3,4$, or 5 , respectively.) Activity was automatically printed out as counts at the end of each of four consecutive 4-min periods for a total session length of $16 \mathrm{~min}$. Each subject was tested on three different occasions, but always at the same TOD. The second session followed the first by $24 \mathrm{~h}$; the third session followed the first by approximately $10(8-12)$ days. Thus, for each subject, there were measures of two types of activity upon initial exposure to a new situation, upon reexposure after $24 \mathrm{~h}$ and after several days. Activity measurements were made in a separate sound-shielded room. A fluorescent light approximately $5 \mathrm{ft}$ directly above the runway was on for all sessions. Illumination at the floor of the runway measured 1,184 lx. To begin each session, the runway was cleaned with a $50 \%$ alcohol solution, then wiped dry. The experimenter reset counters and timer, placed the subject at one end (always the same for every subject) of the runway, put the cover in place, left the room, closed the door, and started the timing sequence. The mouse remained undisturbed for the entire session. Observations of behavior were made through a viewing window in the wall of the room.

\section{RESULTS}

Analyses of variance were computed for the locomotor (photobeam interruption) and investigatory (object contact) activity, measured as counts per 4-min time period. The factors (and the number of categories within factors) for each analysis were: strain $(9) \times \operatorname{sex}(2) \times$ TOD (5) $x$ time period within session $(4) \times$ session (3). Each cell within the analysis included the scores of 10 subjects for a total of 10,800 scores ( 900 between subjects and 12 repeated measures on each subject) in each analysis.

There were complex four-factor interactions, as well as lower order interactions, for both dependent variables. Strain, time period, and session were all statistically significant main effects for both locomotor and investigatory activity. Sex was not a significant main effect for either. TOD was significant only for investigatory activity. The main effects and lower order interactions that appear particularly strong and the significant four-factor interactions will be presented, first for locomotion and then for investigatory activity. The Newman-Keuls procedure (Winer, 1971) was used to test the significance of differences between individual means. Any effect with $p<.01$ was considered statistically significant. The strains will subsequently be referred to with shortened designations: $\mathrm{B} 6$ and /c for the P strains (C57BL/6 and BALB/c, respectively), and the last letter of the strain identifier for the RI strains (e.g., D, E, G, etc. for CXBD, CXBE, CXBG, etc.).

\section{Photobeam Interruptions}

The relevant values from the analysis of locomotion data are presented in Table 1 . Strain, ignoring all other variables, is a strong determinant of locomotor activity. The distribution of scores is D B6 J H G K /c E I. (Strains with an underline in common are not significantly different.)

Within each 16-min session (ignoring the strain, sex, and session dimensions), the amount of locomotor activity decreased significantly with each 4-min time period $(1>3>4)$. Similarly, ignoring strain, sex, and time period, there was a significant decrease in activity between Session 1 and Sessions 2 and $3(1>2=3)$.

Strain interacted with TOD, with session, and with time period. There were also significant interactions between TOD and session, between TOD and time period, and between session and time period, but the second-order interaction among the three was not significant. There was one second-order interaction with sex. Four of the 10 possible second-order interactions are significant.

Three of the five possible third order (i.e., four-factor) interactions were significant, with $p<.01$ : strain $\times$ sex $\times$ TOD $\times$ session, strain $\times$ sex $\times$ session $\times$ time period, and strain $\times$ sex $\times$ TOD $\times$ time period. The fourth-order interaction was not significant. 
Table 1

Locomotor Activity (Photo-Beam Interruptions) Analysis of Variance Source Table

\begin{tabular}{|c|c|c|c|c|c|}
\hline $\begin{array}{c}\text { Source } \\
\text { of Variation }\end{array}$ & $\begin{array}{c}\text { Degrees } \\
\text { of Freedom }\end{array}$ & $\begin{array}{c}\text { Sums } \\
\text { of Squares }\end{array}$ & $\begin{array}{c}\text { Mean } \\
\text { Squares }\end{array}$ & $F$ & $p$ \\
\hline Strain & 8 & 275094.5 & 34386.8 & 19.67 & $<.000001$ \\
\hline Sex & 1 & 5896.3 & 5896.3 & 3.37 & .068227 \\
\hline Strain $\times$ Sex & 8 & 19469.2 & 2433.7 & 1.39 & .204433 \\
\hline A $($ Strain $\times$ Sex $)$ & 162 & 283256.8 & 1748.5 & & \\
\hline Time of Day [TOD] & 4 & 160002.5 & 4000.6 & 3.00 & .018044 \\
\hline TOD $\times$ Strain & 32 & 80508.8 & 2515.9 & 1.88 & .002634 \\
\hline TOD $\times$ Sex & 4 & 5244.0 & 1311.0 & .98 & .417740 \\
\hline TOD $\times$ Strain $\times$ Sex & 32 & 75854.9 & 2370.5 & 1.77 & .006026 \\
\hline TOD $\times$ A $($ Strain $\times$ Sex $)$ & 648 & 865398.1 & 1335.5 & & \\
\hline Session & 2 & 97599.3 & 48799.7 & 75.83 & $<.000001$ \\
\hline Session $\times$ Strain & 16 & 71880.2 & 4492.5 & 6.98 & $<.000001$ \\
\hline Session $\times$ Sex & 2 & 390.2 & 195.1 & .30 & .741024 \\
\hline Session $\times$ Strain $\times$ Sex & 16 & 14037.9 & 877.4 & 1.36 & .159696 \\
\hline Session $\times A($ Strain $\times$ Sex $)$ & 324 & 208496.7 & 643.5 & & \\
\hline Session $\times$ TOD & 8 & 29903.9 & 3738.0 & 6.64 & $<.000001$ \\
\hline Session $\times$ TOD $\times$ Strain & 64 & 63691.4 & 995.2 & 1.77 & .000237 \\
\hline Session $\times$ TOD $\times$ Sex & 8 & 10871.2 & 1358.9 & 2.41 & .025453 \\
\hline Session $\times$ TOD $\times$ Strain $\times$ Sex & 64 & 72227.0 & 1128.5 & 2.00 & .000008 \\
\hline Session $\times$ TOD $\times$ A $($ Strain $\times$ Sex $)$ & 1296 & 729820.7 & 563.1 & & \\
\hline Time Period [TP] & 3 & 380458.1 & 126819.4 & 759.44 & $<.000001$ \\
\hline $\mathrm{TP} \times$ Strain & 24 & 50321.7 & 2096.7 & 12.56 & $<.000001$ \\
\hline $\mathrm{TP} \times \operatorname{Sex}$ & 3 & 1928.2 & 642.7 & 3.85 & .013126 \\
\hline TP $\times$ Strain $\times$ Sex & 24 & 6896.8 & 287.4 & 1.72 & .018854 \\
\hline $\mathbf{T P} \times \mathbf{A}($ Strain $\times$ Sex $)$ & 486 & 81157.8 & 167.0 & & \\
\hline TP $\times$ TOD & 12 & 4575.5 & 381.3 & 2.38 & .004792 \\
\hline TP $\times$ TOD $\times$ Strain & 96 & 28185.3 & 293.6 & 1.83 & .000003 \\
\hline TP $\times$ TOD $\times$ Sex & 12 & 993.3 & 82.8 & .52 & .903176 \\
\hline TP $\times$ TOD $\times$ Strain $\times$ Sex & 96 & 21270.9 & 221.6 & 1.38 & .009862 \\
\hline $\mathrm{TP} \times \mathrm{TOD} \times \mathbf{A}($ Strain $\times$ Sex $)$ & 1944 & 311811.9 & 160.4 & & \\
\hline TP $\times$ Session & 6 & 9047.7 & 1508.0 & 12.41 & $<.000001$ \\
\hline TP $\times$ Session $\times$ Strain & 48 & 20471.4 & 426.5 & 3.51 & $<.000001$ \\
\hline TP $\times$ Session $\times \operatorname{Sex}$ & 6 & 619.3 & 103.2 & .85 & .531418 \\
\hline TP $\times$ Session $\times$ Strain $\times$ Sex & 48 & 9615.9 & 200.3 & 1.65 & .004062 \\
\hline TP $\times$ Session $\times$ A (Strain $\times$ Sex $)$ & 972 & 118130.3 & 121.5 & & \\
\hline TP $\times$ Session $\times$ TOD & 24 & 4058.8 & 169.1 & 1.32 & .136153 \\
\hline TP $\times$ Session $\times$ TOD $\times$ Strain & 192 & 30627.0 & 159.5 & 1.24 & .015507 \\
\hline TP $\times$ Session $\times$ TOD $\times$ Sex & 24 & 2664.0 & 111.0 & .86 & .659651 \\
\hline TP $\times$ Session $\times$ TOD $\times$ Strain $\times$ Sex & 192 & 27744.6 & 144.5 & 1.13 & .110852 \\
\hline TP $\times$ Session $\times$ TOD $\times$ A $($ Strain $\times$ Sex $)$ & 3888 & 499288.5 & 128.4 & & \\
\hline Total & 10799 & 4535510.6 & & & \\
\hline
\end{tabular}

Note-Brackets indicate abbreviations used in the table for sources of variation. " $\mathrm{A}$ " represents the subjects factor in each error term.

Strain $\times \operatorname{sex} \times$ TOD $\times$ session. Within the distribution of mean scores, the relative positions and the statistical relationships of the nine strains change with TOD, with session, and with sex of the subject. These relationships are shown in Figure 1. (All differences mentioned subsequently, unless indicated otherwise, are significant, with $p<.01$ or less.)

In only one instance during Sessions 1,2 , or 3 do the RI strains segregate about the $P$ strains into a clear, statistically determinable dichotomy: females at TOD 4 , Session 3.

The effect of TOD on the amount of locomotion varied among the nine strains. Males and females of both the $P$ and the RI strains exhibited a variety of responses to TOD in the three sessions, such that there is no clear pattern.

With respect to changes in activity between sessions for each TOD and sex, there were more instances of significant changes in locomotor activity between sessions than there were instances of no change, but the direction and pattern of these changes varied extensively (Table 2 ). This is reflected in test-retest reliabilities (determined by correlating Session 1 with Session 2 scores for the 10 subjects within each strain $\times$ sex $\times$ TOD group), which were generally not significant. The 13 significant coefficients ranged from .953 to .772 , and they were scattered with respect to strain, TOD, and sex. Four modes of response, which differ in frequency of occurrence, may be identified (Table 2).

Interactions involving time periods. The remaining two significant third-order interactions involved time period (within sessions) as a factor. (Each session was measured as four consecutive 4-min time periods.) The results of these interactions, in summary, indicate that for most strains, for both sexes, and at most TODs, there was a significant decline in amount of locomotion over the 16-min session. However, there were notable exceptions. The most common pattern of decline was for the amount 

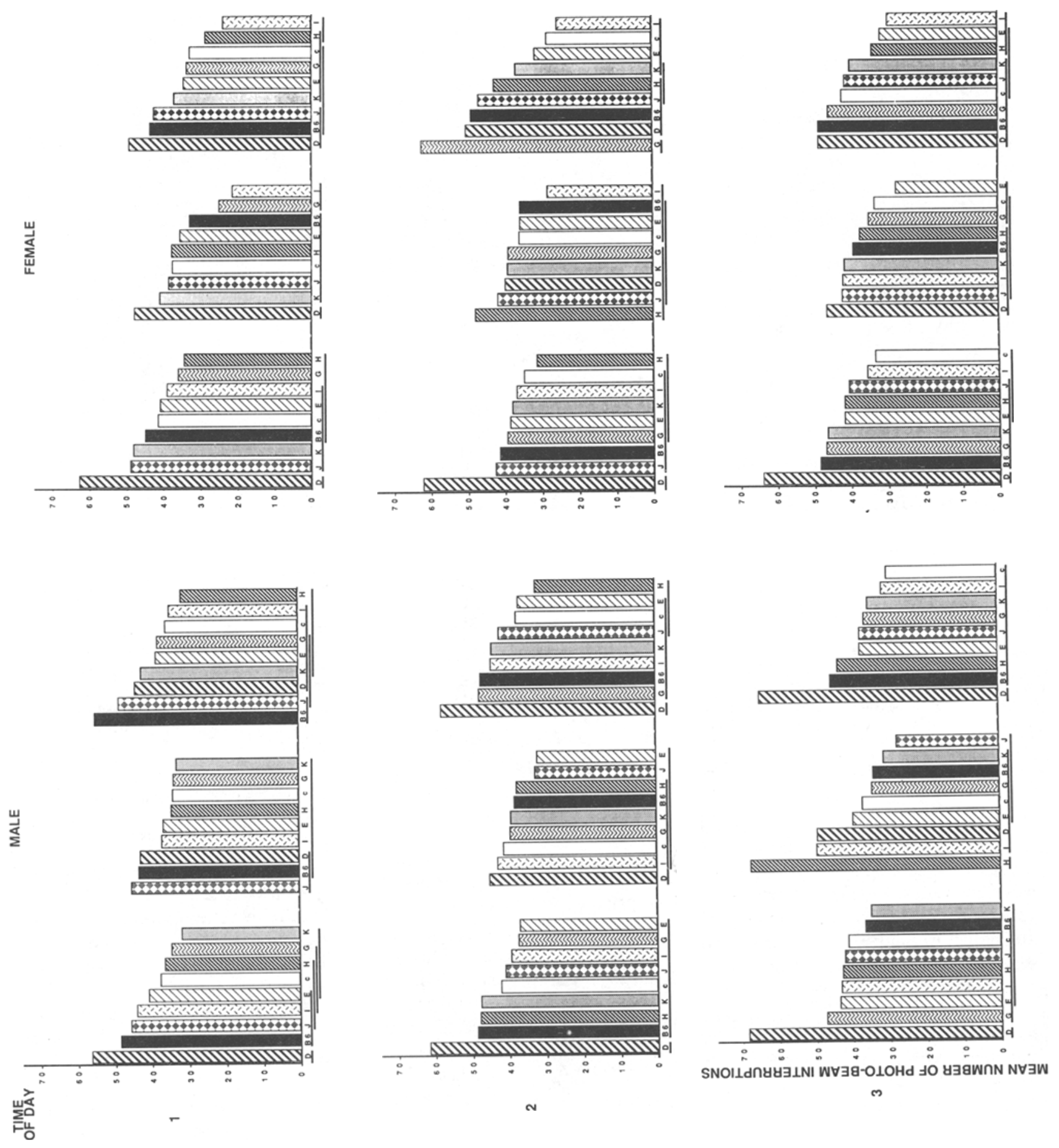

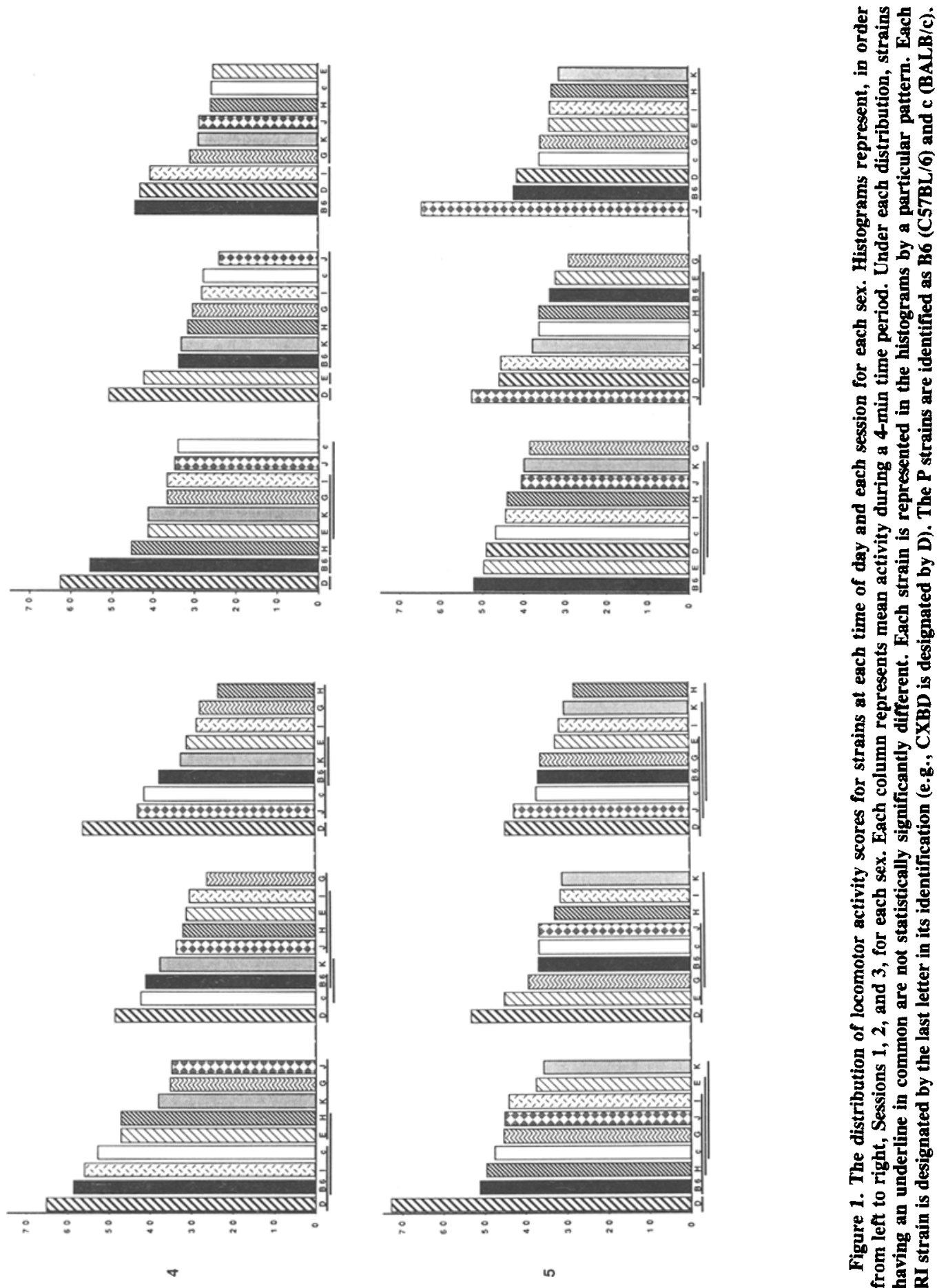

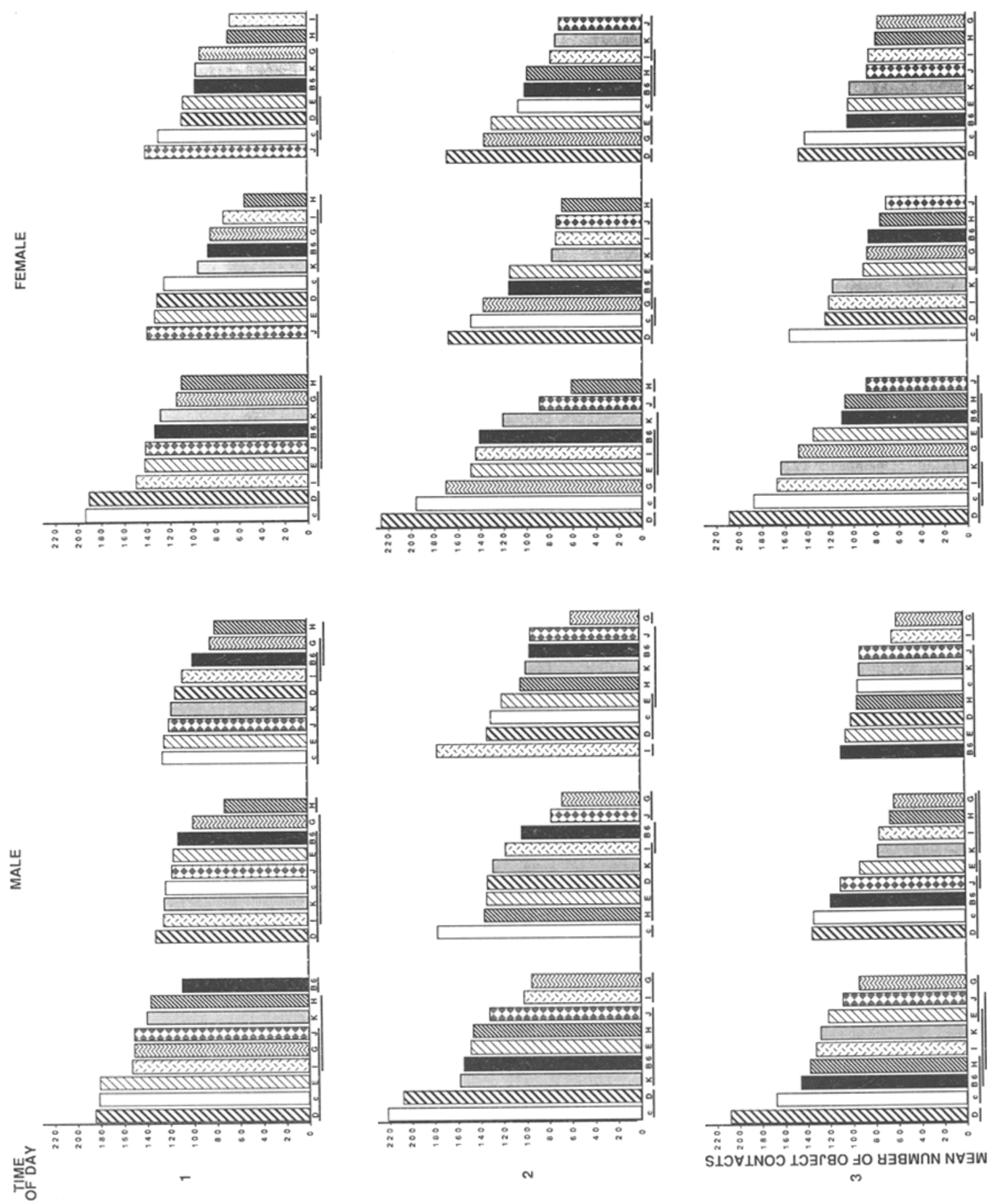

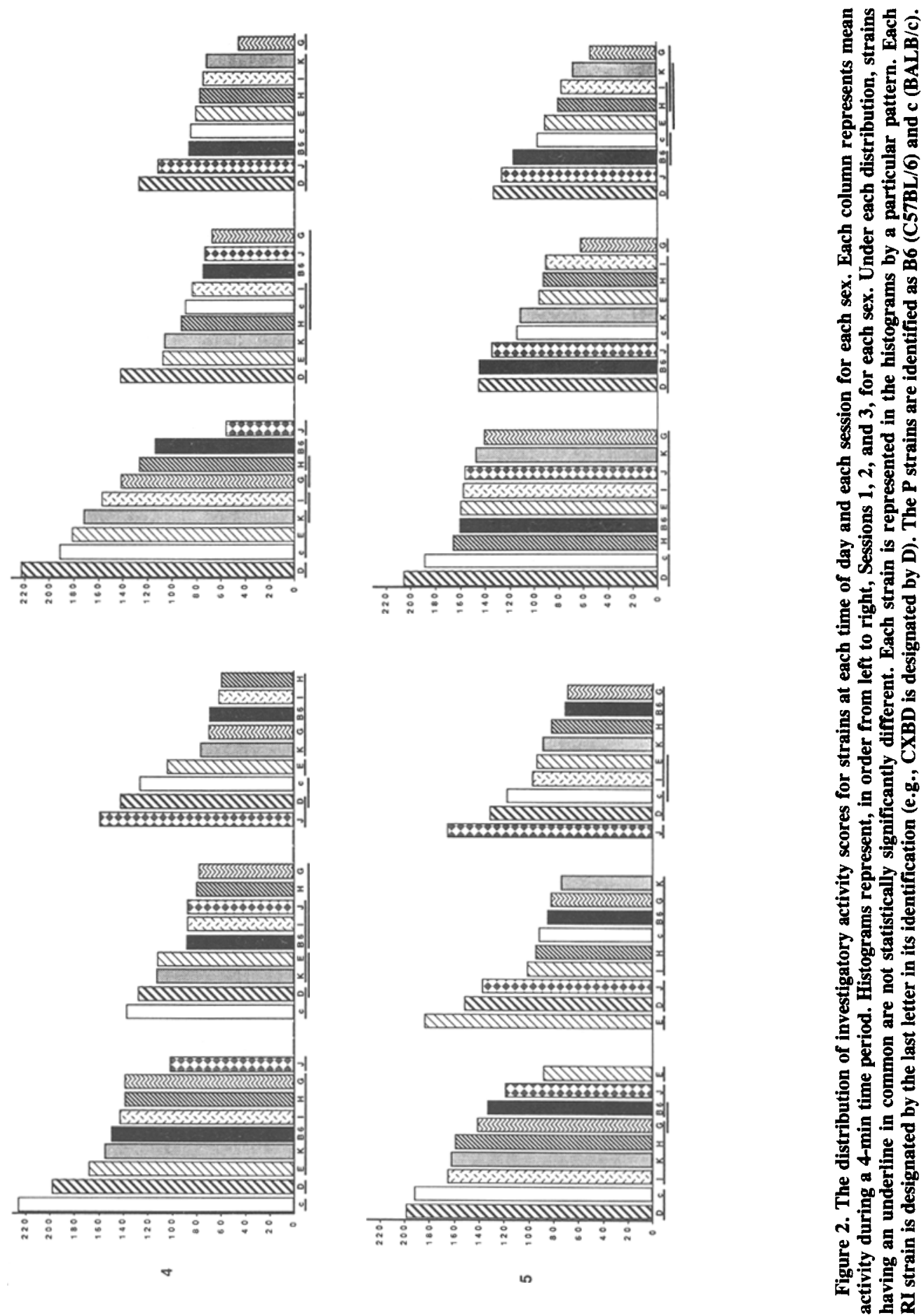
Table 2

Changes in Locomotor Activity Between Sessions for Each Combination of Strain, Sex, and Time of Day

\begin{tabular}{cccccccccc}
\hline \multirow{2}{*}{$\begin{array}{c}\text { Time } \\
\text { of Day }\end{array}$} & B6 & D & E & G & H & I & J & K & /c \\
\hline & & \multicolumn{7}{c}{ Males } \\
1 & $\dagger$ & $*$ & n.s. & n.s. & n.s. & $*$ & n.s. & $\#$ & n.s. \\
2 & $\dagger$ & $\dagger$ & n.s. & $\#$ & $*$ & n.s. & n.s. & n.s. & n.s. \\
3 & $\#$ & n.s. & n.s. & $*$ & $\#$ & n.s. & $\dagger$ & n.s. & $*$ \\
4 & $*$ & $\dagger$ & $*$ & $*$ & $*$ & $*$ & $\#$ & n.s. & $*$ \\
5 & $*$ & $*$ & $*$ & $*$ & $*$ & $*$ & n.s. & n.s. & $*$ \\
& & & & Females & & & & \\
1 & $\dagger$ & $*$ & n.s. & $\dagger$ & n.s. & $*$ & $\dagger$ & $*$ & $*$ \\
2 & $\#$ & $\dagger$ & n.s. & $\#$ & $\#$ & $*$ & n.s. & n.s. & $*$ \\
3 & $\dagger$ & $*$ & $*$ & $\dagger$ & $*$ & $*$ & n.s. & n.s. & $\#$ \\
4 & $\dagger$ & $*$ & $*$ & n.s. & $*$ & $\dagger$ & $\dagger$ & $*$ & $*$ \\
5 & $*$ & n.s. & $*$ & $\dagger$ & $*$ & n.s. & $\#$ & n.s. & $*$ \\
\hline
\end{tabular}

Note-The pattern of activity change over Sessions 1,2 , and 3 is indicated by * $(1>2=3,1>2>3$, or $1=2>3$; Response Mode 1$)$, n.s. (not significantly different; Response Mode 2 ), $\dagger(1=3>2$ or $1>3>2$; Response Mode 3), or \# (3>1=2 or $3=2>1$; Response Mode 4).

of locomotion to be significantly greater in the first 4-min time period than in the remaining three. In Time Period 1, if there was a significant effect, the amount of locomotion was always greater than in Time Period 4; however, in some instances in Periods 2 and 3, the amount was not significantly different from either extreme. For $24 \%$ of the comparisons in each of the two interactions, there was no significant decline in within-session activity. One strain in particular, G, had few instances of activity decline within sessions (males in Session 3, ignoring TOD; males at TOD 2 and females at TOD 1, ignoring sessions). Other strains in which one or more comparisons (but fewer than $50 \%$ of the comparisons for each strain) showed no decline in within-session activity included $\mathbf{H}$, I, J, K, and /c. All strains except G had statistically significant reductions in activity level within Session 1.

\section{Object Contacts}

The main effects of strain, TOD, session, and time period were statistically significant at well beyond the $p<.01$ level (Table 3). The distribution of strains was (D /c E K J B6 I H G). Object contacts at TOD 2 were significantly greater than at TODs 3 and 4 , with those at TODs 1 and 5 not being statistically significantly different from either extreme (25143). There were significant declines in object contacts between successive sessions $(1>2>3)$ and also between time periods within sessions $(1=2>3>4)$. Sex, although it was not a main effect, did interact with the other variables in several instances (Table 3).

Activity change within sessions varied significantly with strain and session (strain $\times$ session $\times$ time period interaction). During Session 1, three strains (E, K, /c) exhibited a decrement in activity between Time Periods 1 and 4; three strains (B6, D, I) had an increase between Time Periods 1 and 2, followed by a return, in Time Periods 3 and 4, to the level of Time Period 1; two strains
(G, J) showed no significant activity change during the session; one strain $(\mathrm{H})$ displayed increasing activity such that Time Period 1 had the lowest number and Time Period 4 had the greatest number of object contacts. In Session 2, D, E, and /c exhibited a decline in activity between Time Periods 1 and 4, whereas the six remaining strains had no significant activity change during the session. In Session 3, six strains showed this same pattern of decline in number of object contacts between Time Periods 1 and 4. B6, G, and $H$ had no significant change in investigatory activity during Session 3 .

Strain $\times$ sex $\times$ TOD $\times$ session. One of the five possible third-order interactions (strain $\times \operatorname{sex} \times$ TOD $\times$ session) is statistically significant. The fourth-order interaction was not significant. The distributions of scores among the nine strains for each sex, TOD, and session are depicted in Figure 2. In Session 1, the /c registered significantly more object contacts than did the B6 at each TOD, with the exception of males at TOD 3. D and /c were consistently the highest scoring strains, more often than not having statistically significantly higher activity than all other strains. B6, on the other hand, was statistically significantly lower than all other strains in only one instance (males at TOD 1). The relationships among B6, /c, and the RI strains changed considerably as a function of sex and TOD.

As may be seen in Figure 2, the changes with TOD in object-contact activity as a function of strain and sex were quite variable in all three sessions. Although some strains tended to be more consistent than others, with respect to TOD activity pattern among sessions and between sexes, recurring patterns are not readily discernible between strains along either dimension.

Most of the strains showed a significant reduction in object contacts between sessions. Typically, either the activity levels for Sessions 2 and 3 were not statistically different from one another, but both were significantly lower than were the activity levels for Session 1 $(1>2=3)$, or the activity levels for the sessions were significantly different in the order $1>2>3$. The changes in object contact activity between sessions for each strain, sex, and TOD are shown in Table 4. Significant test-retest reliabilities (18 out of 90 ) ranged from .953 to .764 . As with locomotor activity, they were scattered among the groups without a discernible pattern.

\section{DISCUSSION}

\section{Initial Assessment (Session 1)}

The present results are consistent with numerous earlier studies that found that B6 mice are more active, in terms of moving about from one place to another, than are /c mice. These results are also consistent with the previous finding (Peeler \& Nowakowski, 1987) that the converse is true for investigatory activity. These findings are extended in the present study to females. If a single gene is a major determinant of either type of activity, there should be a clustering of activity scores of the RI strains 
Table 3

Investigatory Activity (Object Contacts) Analysis of Variance Source Table

\begin{tabular}{|c|c|c|c|c|c|}
\hline $\begin{array}{c}\text { Source } \\
\text { of Variation } \\
\end{array}$ & $\begin{array}{c}\text { Degrees } \\
\text { of Freedom }\end{array}$ & $\begin{array}{c}\text { Sums } \\
\text { of Squares } \\
\end{array}$ & $\begin{array}{c}\text { Mean } \\
\text { Squares }\end{array}$ & $F$ & $p$ \\
\hline Strain & 8 & 4155610.66 & 519451.3 & 42.87 & $<.000001$ \\
\hline $\operatorname{Sex}$ & 1 & 20797.2 & 20797.2 & 1.72 & .191549 \\
\hline Strain $\times$ Sex & 8 & 236442.9 & 29555.4 & 2.44 & .016157 \\
\hline A $($ Strain $\times$ Sex $)$ & 162 & 1962965.4 & 12117.1 & & \\
\hline Time of Day [TOD] & 4 & 227376.1 & 56844.0 & 5.67 & 000173 \\
\hline TOD $\times$ Strain & 32 & 998800.8 & 31212.5 & 3.11 & $<.000001$ \\
\hline TOD $\times$ Sex & 4 & 135085.0 & 33771.3 & 3.37 & .009635 \\
\hline TOD $\times$ Strain $\times$ Sex & 32 & 1156213.7 & 36131.7 & 3.61 & $<.000001$ \\
\hline TOD $\times$ A $($ Strain $\times$ Sex $)$ & 648 & 6494641.7 & 10022.6 & & \\
\hline Session & 2 & 5446130.1 & 2723065.0 & 654.00 & $<.000001$ \\
\hline Session $\times$ Strain & 16 & 1010710.3 & 63169.4 & 15.17 & $<.000001$ \\
\hline Session $\times$ Sex & 2 & 9972.0 & 4986.0 & 1.20 & .302529 \\
\hline Session $\times$ Strain $\times$ Sex & 16 & 204990.4 & 12811.9 & 3.08 & .000072 \\
\hline Session $\times A($ Strain $\times$ Sex $)$ & 324 & 1349039.6 & 4163.7 & & \\
\hline Session $\times$ TOD & 8 & 207074.7 & 25884.3 & 6.78 & $<.000001$ \\
\hline Session $\times$ TOD $\times$ Strain & 64 & 1032705.8 & 16136.0 & 4.23 & $<.000001$ \\
\hline Session $\times$ TOD $\times$ Sex & 8 & 45948.1 & 5743.5 & 1.50 & .152440 \\
\hline Session $\times$ TOD $\times$ Strain $\times$ Sex & 64 & 795062.6 & 12422.9 & 3.25 & $<.000001$ \\
\hline Session $\times$ TOD $\times$ A $($ Strain $\times$ Sex $)$ & 1296 & 4946358.3 & 3816.6 & & \\
\hline Time Period [TP] & 3 & 510340.4 & 170113.5 & 149.99 & $<.000001$ \\
\hline TP $\times$ Strain & 24 & 324641.0 & 13526.7 & 11.93 & $<.000001$ \\
\hline $\operatorname{TP} \times \operatorname{Sex}$ & 3 & 15761.8 & 5253.9 & 4.63 & .003329 \\
\hline $\mathrm{TP} \times$ Strain $\times$ Sex & 24 & 55341.5 & 2305.9 & 2.03 & .002936 \\
\hline$T P \times A($ Strain $\times$ Sex $)$ & 486 & 55119.0 & 1134.2 & & \\
\hline TP $\times$ TOD & 12 & 22234.0 & 1852.8 & 1.69 & .062919 \\
\hline TP $\times$ TOD $\times$ Strain & 96 & 147802.1 & 1539.6 & 1.40 & .007363 \\
\hline TP $\times$ TOD $\times$ Sex & 12 & 18912.2 & 1576.0 & 1.43 & .144824 \\
\hline $\mathrm{TP} \times \mathrm{TOD} \times$ Strain $\times$ Sex & 96 & 143563.6 & 1494.5 & 1.36 & .013110 \\
\hline $\mathrm{TP} \times \mathrm{TOD} \times \mathrm{A}($ Strain $\times$ Sex $)$ & 1944 & 2136911.7 & 1099.2 & & \\
\hline TP $\times$ Session & 6 & 60601.7 & 10100.3 & 11.42 & $<.000001$ \\
\hline $\mathrm{TP} \times$ Session $\times$ Strain & 48 & 146235.8 & 3046.6 & 3.44 & $<.000001$ \\
\hline $\mathrm{TP} \times$ Session $\times$ Sex & 6 & 6656.5 & 1109.4 & 1.25 & .278181 \\
\hline $\mathrm{TP} \times$ Session $\times$ Strain $\times$ Sex & 48 & 39348.0 & 819.8 & .93 & .610096 \\
\hline TP $\times$ Session $\times$ A $($ Strain $\times$ Sex $)$ & 972 & 859779.5 & 884.5 & & \\
\hline TP $\times$ Session $\times$ TOD & 24 & 16573.0 & 690.5 & .75 & .802561 \\
\hline TP $\times$ Session $\times$ TOD $\times$ Strain & 192 & 201659.7 & 1050.3 & 1.14 & .095175 \\
\hline TP $\times$ Session $\times$ TOD $\times$ Sex & 24 & 26495.3 & 1104.0 & 1.20 & .228716 \\
\hline TP $\times$ Session $\times$ TOD $\times$ Strain $\times$ Sex & 192 & 199742.5 & 1040.3 & 1.13 & .110852 \\
\hline $\mathrm{TP} \times$ Session $\times$ TOD $\times$ A $($ Strain $\times$ Sex $)$ & 3888 & 3568129.5 & 917.7 & & \\
\hline Total & 10799 & 39487854.1 & & & \\
\hline
\end{tabular}

Note-Brackets indicate abbreviations used in the table for sources of variation. " $A$ " represents the subjects factor in each error term.

about those of the $P$ strains to form a statistically demonstrable dichotomy (Bailey, 1981). Although the P strains are significantly different in three instances with respect to locomotor activity in Session 1 (males at TOD 1; females at TODs 3 and 4; see Figure 1), the RI strains do not clearly dichotomize about them. Thus, the conclusion of Moisset (1977), Oliverio et al. (1973), and Van Abeelen (1977) that there is one major gene determinant for exploratory activity (measured as locomotion) is not supported at least for these particular strains with these particular measures of activity. In contrast, investigatory activity by the $P$ strains was significantly different in 9 of the 10 comparisons for Session 1 (Figure 2). There was a statistically substantiated dichotomy among the 9 strains, however, in only one instance (females at TOD 5). Most often, the strains appeared to form three or more groups. The implication, using the formula described by Bailey (1981), is that there may be at least three determining genetic loci. There are similar implications for Sessions 2 and 3 . It is clear that there are definite genetic influences upon both investigatory and locomotor activity, the expressions of which vary as a function of time of day and previous experience.

It was somewhat surprising to find B6 mice exhibiting more locomotor activity than /c mice at only one time of day (TOD 1), in view of the many reports of this difference (Blizard \& Bailey, 1979; Messeri, Oliverio, \& Bovet, 1972; Oliverio \& Castellano, 1974; Oliverio et al., 1973; Peeler \& Nowakowski, 1987; Shuster, Webster, Yu, \& Eleftheriou, 1975). However, reports of greater activity in BALB/c do exist (Lassalle \& le Pape, 1978; le Pape \& Lassalle, 1984; Simmel \& Eleftheriou, 1977), and the commonly reported difference has been demonstrated to disappear under some testing conditions (Blizard \& Bailey, 1979; Lassalle \& le Pape, 1978). It is possible that the B6 mice were exhibiting neophobic inhibition of 
Table 4

Changes in Investigatory Activity Between Sessions

for Each Combination of Strain, Sex, and Time of Day

\begin{tabular}{|c|c|c|c|c|c|c|c|c|c|}
\hline \multirow{2}{*}{$\begin{array}{c}\text { Time } \\
\text { of Day }\end{array}$} & \multicolumn{9}{|c|}{ Strain } \\
\hline & B6 & $\mathrm{D}$ & $\mathrm{E}$ & G & $\mathrm{H}$ & I & $\mathbf{J}$ & $\mathbf{K}$ & $/ \mathrm{c}$ \\
\hline \multicolumn{10}{|c|}{ Males } \\
\hline 1 & n.s. & * & * & $*$ & $*$ & * & $*$ & n.s. & * \\
\hline 2 & $*$ & * & $*$ & $*$ & * & $\#$ & $*$ & $*$ & * \\
\hline 3 & * & * & * & $*$ & $\dagger$ & * & n.s. & $*$ & * \\
\hline 4 & $*$ & $*$ & * & $*$ & * & * & $\#$ & * & * \\
\hline 5 & $*$ & $*$ & * & $*$ & $*$ & * & $\#$ & $*$ & $\dagger$ \\
\hline \multicolumn{10}{|c|}{ Females } \\
\hline 1 & * & $*$ & * & $*$ & $*$ & $*$ & n.s. & * & $*$ \\
\hline 2 & * & $*$ & * & n.s. & $\#$ & * & n.s. & $*$ & $*$ \\
\hline 3 & $\dagger$ & $\dagger$ & * & $*$ & $*$ & * & $\dagger$ & $*$ & * \\
\hline 4 & $*$ & $*$ & * & $*$ & $*$ & $*$ & $\#$ & $*$ & $*$ \\
\hline 5 & $*$ & * & * & $*$ & * & * & $*$ & $*$ & * \\
\hline
\end{tabular}

Note-The pattern of activity change over Sessions 1, 2, and 3 is indicated by $*(1>2=3,1>2>3$, or $1=2>3$; Response Mode 1$)$, n.s. (not significantly different; Response Mode 2$), \dagger(1=3>2$ or $1>3>2$; Response Mode 3$)$, or $\#(3>1=2$ or $3=2>1$; Response Mode 4$)$.

locomotion in response to the objects, whereas this was not a factor for the $/ \mathrm{c}$ mice. However, the objects were not comparable, in terms of brightness cues, to the dramatic black and white stripe and checkerboard patterns that evoked an apparently severe neophobia in this same strain (see Simmel \& Eleftheriou, 1977). Rather, the objects were of similar brightness to the floor and walls of the runway but differed considerably in form and texture. An earlier study (Foshee et al., 1965), using a similar runway but only one novel object located at one end of the device, found similar levels of locomotion and comparable relationships between $\mathrm{B} 6$ and $/ \mathrm{c}$ for both measures of activity. Thus, if neophobia was affecting B6 locomotor activity, one distant object was apparently as effective as several that allowed little distance between mouse and object.

At no TOD did the distribution of strains for either activity (Figures 1 and 2) replicate the previous study using the same device (Peeler \& Nowakowski, 1987). TOD, however, was not controlled in the earlier study. Consistent with the findings of Peeler and Nowakowski (1987), the strain CXBD exhibited a consistently high level of both investigatory and locomotor activity.

The significant main effect of strain and the pervasiveness of this factor in the various interactions indicates that the major genetic influences on activity are autosomal. Nevertheless, there are sex-related influences, as indicated by the various significant interactions with sex.

An influence of TOD is also evident, particularly for investigatory activity. Nevertheless, given an activity score, it would be difficult to predict either locomotor or investigatory activity level at some other TOD without considering strain, sex, and session. It remains to be determined whether or not these effects are dependent upon the light cycle, or whether or not they are independently circadian.

From the results reported by Lassalle and le Pape (1978) and Oliverio and Malorni (1979), one would predict, in both $P$ strains, one high point in activity occurring around the time of light onset (i.e., near TOD 1 in the present study) and at the time of light off (TODs 4 and 5 in the present study). Indeed, in the present study, there are some occurrences of increased activity at one or both of these times, but there are as many, or more, occurrences of greatest activity at other times during the day. One must conclude that the circadian effects, whether manifestations of light entrainment or other influences, are modulated by a combination of genetic and experiential factors.

Although this study measured activity, what was actually being assessed might have been light-induced behavioral inhibition (i.e., the extent to which each strain and sex suppresses its "normal" behavior in a specific situation under bright illumination). Measurement of activity using this same paradigm, but with dim or no light, also needs to be done.

\section{Within-Session Habituation}

Most strains at most TODs showed a significant withinsession decline in locomotor activity between Time Periods 1 and 4. With investigatory activity, on the other hand, within-session habituation was relatively infrequent. This difference supports the conclusion that these two measures of activity are assessing two different traits. (Activity decrements in the present study are presumed to be manifestations of stimulus habituation or motivational change not related to physical, muscular fatigue.)

The observed decline in locomotion is contrary to the report by Oliverio and Messeri (1973) that B6 mice exhibited "no sensible decrement" of locomotor activity between the first and second of two 10-min periods in a toggle cage device. With the present data, the decline is generally relatively abrupt, in most instances occurring between Time Periods 1 and 2 (i.e., in the first $8 \mathrm{~min}$ of the session). This discrepancy may reflect apparatus differences (e.g., the greater length of traverse in the present study) and/or a greater confounding of the two types of activity in the toggle cage. A major exception is the $\mathbf{G}$ strain, in which no significant change in locomotor activity is the rule.

There are differences among strains such that they form dichotomies (habituation or no habituation) at most times of day. In none of the three instances of dichotomous clustering of scores with the P strains in different groups (females at TODs 1, 2, and 4) is the distribution of withinsession habituation among strains the same as that reported in a previous study (Peeler \& Nowakowski, 1987). Procedural differences between the studies, as noted above, presumably led to different results. None of these three dichotomies conform to any of those reported previously in the literature for other behaviors or for the anatomical trait Hld.

The tendency for locomotor activity to habituate within a testing session appears unrelated to the amount of locomotor activity exhibited. The occurrence of a decrement in activity is not correlated with the absolute value of the locomotor score at any of the TODs. 


\section{Between-Session Habituation}

Both locomotor and investigatory activity were strongly affected by prior exposure to the test situation. Particularly with respect to locomotor activity, changes over these two intervals varied with strain, TOD, and sex. This effect of prior exposure, which persists for up to several days, implies that subjects, under appropriate conditions of TOD, strain, and sex, retain information about the stimulus situation even over the extended intersession interval.

Although there were several types of response to the repeated measurement of activity, the strains may be dichotomized in terms of showing between-session habituation (Response Modes 1 and 3) or no habituation (Response Modes 2 and 4). In several instances, the P strains were different with respect to the habituation of locomotor activity, indicating predominant influence of a single genetic locus; however, none of the RI strain distribution patterns was in concordance with those of Hld or of behaviors described in the literature. Furthermore, there appears to be no relationship between within-session habituation of locomotor activity and between-session activity changes. It should be noted that the apparent (statistically substantiated) segregation of response change over sessions into four modes may well indicate multigenic determination of this trait. Mode of habituation may be a relevant dimension for the investigation of genetic and circadian influences on behavior.

The extended time between Sessions 2 and 3 led to several instances of dishabituation (Response Mode 3) with respect to locomotor activity in B6 mice, but not in $/ \mathrm{c}$ mice. This is in contrast to the study by Foshee et al. (1965) in which C57BL/6 and BALB/c mice were tested in a runway on each of 7 consecutive days: neither strain showed any increase after the initial decrease between Days 1 and 2. Dishabituation occurs much less frequently for investigatory activity than for locomotor activity, indicating that there tends to be retention over longer periods of time of those factors' inducing investigatory, as contrasted with locomotor, habituation. This and the other differences between the two measures of activity reinforce the concept of two separable, perhaps independent, behaviors that are manifestations of two different functional systems.

It is of interest that habituation (defined as an activity decrement) both within and between sessions is affected by strain, time of day, and sex, but that the two forms of habituation appear to be independent. The possible relationship to working and reference memory (Olton, Becker, \& Handelmann, 1979) is a point of interest for future study.

The time of day at which measurement is made, the trait being measured, previous experience, and the strain and sex of the subject are recognized as at least potentially important by all investigators, but their interaction often may not be considered (Hobbs \& Goldberg, 1987; Terman, 1983). The complex relationships among these variables are elaborated by the current data, but further study is required to clarify them. The understanding of specific behaviors and their functions in the context of the real world requires investigation of interactions.

\section{REFERENCES}

BAILEY, D. W. (1981). Recombinant inbred strains and bilineal congenic strains. In H. L. Foster, J. D. Small, \& J. G. Fox (Eds.), The mouse in biomedical research: Volume I. History, genetics, and wild mice (pp. 223-239). New York: Academic Press.

BlizARD, D. A., BAILEY, D. W. (1979). Genetic correlation between open-field activity and defecation: Analysis with the $\mathrm{CXB}$ recombinant inbred strains. Behavior Genetics, 9, 349-357.

Chozick, B. S. (1983). The behavioral effects of lesions of the hippocampus: A review. International Journal of Neuroscience, 22, 63-80.

DeFries, J. C., Grevais, M. C., \& Thomas, E. A. (1978). Response to $\mathbf{3 0}$ generations of selection for open-field activity in laboratory mice. Behavior Genetics, 8, 3-13.

DeFries, J. C., Hegmann, J. P., \& Ha lcomb, R. A. (1974). Response to 20 generations of selection for open-field activity in mice. Journal of Behavioral Biology, 11, 481-495.

Foshee, D. P., Vierck, C. J., JR., Meier, G. W., \& Federspiel, C. (1965). Simultaneous measure of general activity and exploratory behavior. Perceptual \& Motor Skills, 20, 445-451.

HobBs, S. H., GoldererG, S. J. (1987). Circadian thythms and animal behavior research: A follow-up survey. Psychobiology, 15, 192-194.

ISAACSON, R. L., MCCLEARN, G. E. (1978). The influence of brain damage on locomotor behavior of mice selectively bred for high or low activity in the open field. Brain Research, 150, 559-567.

Lassalle, J. M., \& LE PAPE, G. (1978). Locomotor activity of two inbred strains of mice in a seminatural and a breeding cage environment. Behavior Genetics, 8, 371-376.

le Pape, G., \& Lassalle, J. M. (1984). A developmental genetic analysis of locomotor activity in mice: Maternal effects in the BALB/c and C57BL/6 strains and heredity in $\mathrm{F}_{1}$ hybrids. Behavior Genetics, 14, 21-29.

Messeri, P., Oliverio, A., Bovet, D. (1972). Relations between avoidance and activity: A diallel study in mice. Behavioral Biology, 7, 733-742.

MoIsset, B. (1977). Factors contributing to the modulation of norepinephrine uptake by synaptosomes from mouse brain cortex. Brain Research, 121, 113-120.

NowakowsKI, R. S. (1984). The mode of inheritance of a defect in lamination in the hippocampus of BALB/c mice. Journal of Neurogenetics, 1, 249-258.

Oliverio, A., Castellano, C. (1974). Genotype-dependent sensitivity and tolerance to morphine and heroin: Dissociation between opiate-induced running and analgesia in the mouse. Psychopharmacologia, 39, 13-22.

Oliverio, A., Eleftheriou, B. E., Bailey, D. W. (1973). Exploratory activity: Genetic analysis of its modification by scopolamine and amphetamine. Physiology \& Behavior, 10, 893-899.

Oliverio, A., \& Malorni, W. (1979). Wheel running and sleep in two strains of mice: Plasticity and rigidity in the expression of circadian rhythmicity. Brain Research, 163, 121-133.

Oliverio, A., \& Messeri, P. (1973). An analysis of single-gene effects on avoidance, maze, wheel running, and exploratory behavior in the mouse. Behavioral Biology, 8, 771-783.

Olton, D. S., Becker, J. T., \& Handelmann, G. E. (1979). Hippocampus, space, and memory. Behavioral \& Brain Sciences, 2, 313-365

Peeler, D. F. (1972). Activity as a function of genetic variables and opportunity for exploration. Psychonomic Science, 27, 176-178.

Peeler, D. F. (1968). [Activity levels in two inbred mouse strains at two times of day]. Unpublished raw data.

Peeler, D. F., Nowakowski, R. S. (1987). Genetic factors and the measurement of exploratory activity. Behavioral \& Neural Biology, 48, 90-103.

Shuster, L., Webster, G. W., Yu, G., \& Eleftheriou, B. E. (1975). 
A genetic analysis of the response to morphine in mice: Analgesia and running. Psychopharmacologia, 42, 249-254.

SIMMEL, E. C. (1976). Behavior genetic analysis of exploratory behavior and activity through use of recombinant inbred strains of mice: A progress report. Behavior Genetics, 6, 117-118.

Simmel, E. C., Eleftheriou, B. E. (1977). Multivariate and behavior genetic analysis of avoidance of complex visual stimuli and activity in recombinant inbred strains of mice. Behavior Genetics, 7 , 239-250.

Simmel, E. C., Eleftheriou, B. E., Haber, S. B., \& Harshfield, G. (1977). A genetic model for exploratory behavior and its relationship to age and sex differences. Behavior Genetics, 7, 87.
TERman, M. (1983). Behavioral analysis and circadian rhythms. In M. D. Zeiler \& P. Harzen (Eds.), Advances in analysis of behaviour: Biological factors in learning (Vol. 3, pp. 103-141). New York: Wiley.

VAN ABEELEN, J. H. (1977). Rearing responses and locomotor activity in mice: Single-locus control. Behavioral Biology, 19, 401-404.

WINER, B. J. (1971). Statistical principles in experimental design. New York: McGraw-Hill.

(Manuscript received October 9, 1989; revision accepted for publication April 5, 1990.) 